\title{
The relationship between vitamin D status and graft function in renal transplant recipients
}

\author{
Bilge Karatoy Erdem', Vural Taner Yilmaz², Gultekin Suleymanlar², Filiz Ozcan', Asli Baykal \\ Ataman', Halide Akbas' \\ 'Department of Clinical Biochemistry, Akdeniz University, Antalya, Turkey \\ ${ }^{2}$ Department of Nephrology, Akdeniz University, Antalya, Turkey
}

\begin{abstract}
Objectives: Bone and mineral metabolism disorders are important potential complications after renal transplantation. The purpose of this study was to demonstrate the relationship between vitamin D, 1,25-dihydroxyvitamin D3 [1,25(OH)2D3], calcium, and phosphorus metabolism with graft function in renal transplant recipients.

Methods: This prospective longitudinal study included 30 renal transplant recipients (10 female, 20 male; mean age: $40.30 \pm 12.86$ years). Blood and urine samples were collected before and 6 months after transplantation. Serum creatinine, blood urea nitrogen (BUN), calcium, phosphorus, alkaline phosphatase (ALP), glucose, albumin, parathyroid hormone (PTH), 25-hydroxyvitamin D [25(OH)D], and plasma 1,25(OH)2D3 levels were measured. In addition, the urine protein/creatinine $(\mathrm{P} / \mathrm{C})$ ratio was calculated. The plasma 1,25(OH)2D3 level was determined using liquid chromatography-tandem mass spectrometry.

Results: The posttransplant level of serum phosphorus, PTH, creatinine, BUN and ALP was found to be significantly decreased $(p=0.0001 ; p=0.011$ for ALP). Although the plasma 1,25(OH)2D3 level had significantly increased $(p=0.0001)$ after transplantation, no significant difference in the serum $25(\mathrm{OH}) \mathrm{D}$ level was observed. The urine $\mathrm{P} / \mathrm{C}$ ratio was found to be significantly decreased after transplantation $(p=0.007)$. A deficiency of vitamin $D$ was observed frequently both before (87\%) and after (73\%) transplantation.

Conclusion: Persistent vitamin D deficiency was detected in the recipients even after transplantation, although the serum PTH level decreased. Some studies published to date draw a direct link between serum vitamin D level and graft function; however, evidence for this link was not observed in the present study. Long-term monitoring may be needed to evaluate the correlation between vitamin $\mathrm{D}$ level and graft function.

Keywords: 1,25-dihydroxyvitamin D3, graft function, liquid chromatography-tandem mass spectrometry, protein/creatinine ratio, renal transplantation, vitamin $\mathrm{D}$
\end{abstract}

C hronic kidney disease (CKD), which has a high morbidity and mortality rate, negatively affects the quality of life. The incidence of the disease has increased significantly in recent years [1]. Renal replacement therapies, such as dialysis and renal transplantation, are implemented for patients with CKD. In renal transplantation patients, survival and quality of life is improved markedly compared with dialysis patients, and less cardiovascular disease is observed [2]. However, there is still a high risk for acute rejection and chronic allograft nephropathy in renal transplantation [3, 4]. Due to the increasing importance of the renal transplantation, it is very important to reduce major risk factors involved in graft failure.

Vitamin $D$, which plays an important role in the regulation of calcium, phosphorus, and bone metabolism, is a steroid hormone. It is obtained through nutrition and solar radiation. Two hydroxylation steps are required to convert it to the physiologically active form of vitamin $D(1,25$-dihydroxyvitamin $D$, calcitriol). The first step occurs in the liver, producing 25-hydroxyvitamin D3 
[25(OH)D3]. The second hydroxylation step is mainly carried out by the 1a-hydroxylase enzyme in the kidney [5]. Calcitriol levels are usually insufficient in patients whose glomerular filtration rate (GFR) is less than $30 \mathrm{~mL} /$ minute, due to the 1a-hydroxylase enzyme inhibition associated with hyperphosphatemia [6]. Vitamin D deficiency and insufficiency have been reported in the majority of CKD patients [7]. The situation is similar in renal transplantation. Transplant patients must avoid sunlight due to immunosuppressive therapy and there is accelerated vitamin $D$ catabolism as a result of using glucocorticoids. Although vitamin D supplementation is included in the guidelines, it is thought it may be a trigger in cases of hypercalcemia, hyperphosphatemia, or hypoparathyroidism, and is not generally used $[8,9]$. There is still no specific guidance for vitamin D supplementation in renal transplantation patients [1].

Because of the renal protective properties of vitamin $D$, renal graft function is affected when it is deficient. Vitamin D regulates the renin-angiotensin-aldosterone system negatively. Previous research has demonstrated that proteinuria, a risk factor for progressive renal failure, is reduced with vitamin D supplementation $[10,11]$. Vitamin D insufficiency and proteinuria are strongly correlated in renal transplantation recipients [12]. The immune regulatory effects of vitamin D also play an important role in renal transplantation. Calcitriol receptors are available in various immune cells, such as T and B cells, monocytes, and antigen presenting cells. Due to the suppression of helper $T$ cell proliferation and dendritic cell differentiation, calcitriol may be protective in transplantation $[13,14]$.

Accurate measurement of vitamin $D$ is crucial in clinical laboratory settings. Therefore, it requires standardization. Liquid chromatography-tandem mass spectrometry (LC-MS/MS) is the gold standard method for vitamin D measurement [15]. The active form of vitamin $D, 1,25$-dihydroxyvitamin $D$, exhibits an extremely low serum concentration. Thus, its quantification is extremely challenging, even using LC-MS/MS. It requires difficult sample pretreatment procedures, such as solid phase extraction and derivatization. Using an atmospheric pressure chemical ionization (APCl) source to measure the level of vitamins is common, but the research about measuring 1,25(OH)2D3 level using LC-MS/MS with an electro spray ionization (ESI) source is limited.

Since vitamin D deficiency may negatively affect graft function in renal transplant recipients, this study was designed to evaluate vitamin $D$ status and graft function before and after transplantation. The level of 1,25-dihydroxyvitamin D3 was also measured using LC-MS/MS with an ESI source and compared with other parameters.

\section{Materials and Methods}

\section{Design}

Thirty-five living-donor renal transplant recipients were recruited into the study (12 female, 23 male; mean age \pm SD: $40.30 \pm 12.85$ years, $\geq 18$ years old). This prospective, longitudinal

\section{Table 1. Demographic features of the patients}

\begin{tabular}{lc}
\hline & All Patients \\
\hline Recipient age (years) & $40.30 \pm 12.85$ \\
Donor age (years) & $41.43 \pm 12.82$ \\
Gender (female/male) (\%) & $10 / 20$ \\
Body mass index (kg/m²) & $23.74 \pm 4.76$ \\
\hline Type of Renal Replacement Therapy & $\mathrm{n}(\%)$ \\
Peritoneal dialysis D & $5(17)$ \\
Hemodyalisis & $12(40)$ \\
Preemptive & $13(43)$ \\
\hline The Etiology of End-Stage Renal Disease & $\mathrm{n}(\%)$ \\
Glomerulonephritis & $5(16.67)$ \\
Diabetes mellitus & $4(13.33)$ \\
Hypertension & $3(10)$ \\
Vesico urethral reflux & $3(10)$ \\
Polycystic kidney disease & $3(10)$ \\
Etiology unknown & $9(30)$ \\
Other & $3(10)$ \\
Total & $30(100)$ \\
\hline
\end{tabular}

Results are expressed as numbers and percentages.

study was conducted in accordance with the ethical standards of the Akdeniz University Faculty of Medicine ethics committee (approval number: 225) and the Helsinki Declaration, and written informed consent was provided by all of the patients. Five patients who had a transplantation from a cadaveric donor, malignancy, combined (pancreas or liver) transplantation, or graft failure related to surgical causes were excluded from the study. Demographic characteristics, including age, sex, primary disease and dialysis type are presented in Table 1. The kidney graft recipients were managed using the center's protocol, which includes tacrolimus, mycophenolate mofetil, and basiliximab/ everolimus/sirolimus.

\section{Samples}

The samples were collected immediately before and 6 months after transplantation. The samples were centrifuged at 4000 rpm for 5 minutes. The sera, plasma, and urine were stored until the day of analysis at $-80^{\circ} \mathrm{C}$. Estimated GFR (eGFR) was calculated using the Chronic Kidney Disease Epidemiology formula and the serum creatinine values of the patients [16].

\section{Procedure}

Serum creatinine, BUN, calcium, phosphorus, alkaline phosphatase, albumin, and urine creatinine levels were measured using commercial kits and a Roche COBAS-8000 autoanalyzer (Roche Diagnostics, Mannheim, Germany) and colorimetric methods. Urine protein was determined using the turbidimetric method and commercial kits in the COBAS-8000 autoanalyzer. Serum PTH and 25(OH)D levels were measured using commercial kits in a Roche COBAS-e602 autoanalyzer (Roche 
Table 2. Patient parameters before and 6 months after transplantation

\begin{tabular}{lccc}
\hline Parameters & Pretransplant & Posttransplant & P \\
\hline $1,25(\mathrm{OH}) 2 \mathrm{D} 3(\mathrm{pg} / \mathrm{mL})$ & $43.70 \pm 14.15$ & $68.48 \pm 18.35$ & 0.0001 \\
$25(\mathrm{OH}) \mathrm{D}(\mathrm{ng} / \mathrm{mL})$ & $7.74 \pm 6.59$ & $10.46 \pm 5.79$ & 0.102 \\
Ca $(\mathrm{mg} / \mathrm{dL})$ & $8.38 \pm 0.87$ & $9.08 \pm 0.50$ & 0.0001 \\
P $(\mathrm{mg} / \mathrm{dL})$ & $4.78 \pm 1.10$ & $2.90 \pm 0.62$ & 0.0001 \\
CaxP & $39.89 \pm 9.88$ & $26.38 \pm 6.26$ & 0.0001 \\
PTH $(\mathrm{pg} / \mathrm{mL})$ & $424.04 \pm 399.30$ & $116.59 \pm 82.30$ & 0.0001 \\
Creatinine $(\mathrm{mg} / \mathrm{dL})$ & $8.94 \pm 2.85$ & $1.21 \pm 0.29$ & 0.0001 \\
BUN $(\mathrm{mg} / \mathrm{dL})$ & $66.97 \pm 22.98$ & $16.77 \pm 6.63$ & 0.0001 \\
eGFR $(\mathrm{mL} / \mathrm{dk})$ & $6.80 \pm 2.55$ & $73.17 \pm 20.10$ & 0.0001 \\
ALP $(\mathrm{U} / \mathrm{L})$ & $112.63 \pm 40.45$ & $90.77 \pm 23.42$ & 0.011 \\
Urine P/C Ratio & $1.97 \pm 1.02$ & $0.17 \pm 0.11$ & 0.007 \\
\hline
\end{tabular}

25(OH)D: 25-hydroxyvitamin D; 1,25(OH)2D3: 1,25-dihydroxyvitamin D3; ALP: Alkaline phosphatase; BUN: Blood urea nitrogen; Ca: Calcium; CaxP: Calcium-phosphorus; eGFR: Estimated glomerular filtration rate; P: Phosphorus; P/C: Protein/creatinine; PTH: Parathyroid hormone.

${ }^{*} P<0.05$ was considered statistically significant.

Data are given as mean \pm standard deviation.

Diagnostics, Mannheim, Germany) using electrochemiluminescence immunoassay (ECLIA) methods. The detection limit of ECLIA 25(OH)D was noted as $3.00 \mathrm{ng} / \mathrm{mL}$ in the kit insert. ImmuTube LC-MS/MS Extraction Kit (KM1000; Immundiagnostik AG, Besheim, Germany) was used for the plasma $1,25(\mathrm{OH}) 2 \mathrm{D} 3$ analysis. This method is based on the quantitative measurement of $1,25(\mathrm{OH}) 2 \mathrm{D} 3$ in plasma after extraction. Analysis of 1,25(OH)2D3 was performed using the optimized multiple reaction monitoring method in ESI-sourced LCMS8040 triple quadrupole tandem mass spectrometry combined with ultra fast liquid chromatography (LC-20 AD UFLC XR, Shimadzu Corp., Kyoto, Japan). ESI (+) positive mode was used in this analysis.

\section{Statistical Analysis}

All statistical analyses were performed with IBM SPSS Statistics for Windows, Version 20.0 (IBM Corp., Armonk, NY, USA) and a significance level of 0.05 was adopted. The KolmogorovSmirnov test was performed to assess deviation from normal distribution. Quantitative variables were summarized as mean and standard deviation (SD), or as median. Student's t-test or the Mann-Whitney $U$ test was used for comparison of continuous variables between groups. The analysis of correlation was done with the Spearman or Pearson test.

\section{Results}

Patient characteristics and demographic features are shown in Table 1. The mean age of patients was $40.30 \pm 12.86$ years (range: 19-70 years). There were 20 male and 10 female patients. Twelve of the patients received hemodialysis and 5 received peritoneal dialysis treatment before transplantation. A preemptive kidney transplantation was carried out for 13 patients.
Table 2 summarizes the plasma 1,25(OH)2D3, serum creatinine, phosphorus, calcium, PTH, 25(OH)D, BUN, ALP level, and urinary $\mathrm{P} / \mathrm{C}$ ratio of the patients before and 6 months after transplantation. The calcium-phosphorus product value is also provided. The level of $1,25(\mathrm{OH}) 2 \mathrm{D} 3$ showed a significant increase due to the improvement of kidney function after transplantation $(p=0.0001)$, while the serum 25(OH)D level did not increase significantly ( $p=0.102$ ) (Table 2$)$. The serum creatinine, phosphorus, PTH, BUN, and ALP levels significantly decreased after transplantation, while the calcium level increased. Also, though the serum PTH level was significantly lower after transplantation, it was still above the reference ranges. The urine $\mathrm{P} / \mathrm{C}$ ratio was found to have decreased significantly after transplantation $(\mathrm{p}=0.007)$.

Prior to transplantation, $87 \%$ of the recipients had a vitamin D deficiency $(<15 \mathrm{ng} / \mathrm{mL})$, while the proportion was $73 \% 6$ months later. Additionally, vitamin D insufficiency (15-30 ng/ $\mathrm{mL}$ ) was detected in 13\% before transplantation and $27 \% 6$ months after receiving the transplant.

Significantly positive correlations between calcium and 25(OH)D ( $r=0.447 ; p=0.013)$, as well as PTH and ALP $(r=0.843$; $p=0.0001$ ) levels were observed before transplantation. In addition, significantly negative correlations between PTH, ALP, creatinine and eGFR $(r=-0.395, p<0.05 ; r=-0.421, p<0.05 ; r=-$ $0.892, p=0.0001$, respectively) were found. Significantly negative correlations between PTH and ALP and calcium ( $r=-0.467$, $p<0.01 ; r=-0.431, p<0.05$, respectively) were also found. No significant correlation was observed between 1,25(OH)2D3 level and other parameters before transplantation. After the transplantation, a negative correlation was seen between serum 25(OH)D and PTH level ( $r=-0.365 ; p=0.047)$. Significant correlations between proteinuria expressed as $\mathrm{P} / \mathrm{C}$ ratio and $25(\mathrm{OH}) \mathrm{D}$ or $1,25(\mathrm{OH}) 2 \mathrm{D} 3$ were not observed. 


\section{Discussion}

Metabolic complications began to be more frequently encountered due to prolongation of graft survival after transplantation. Bone and mineral metabolism disorders are very important for renal transplant recipients. Therefore, we evaluated some parameters related to bone metabolism, vitamin $D$ status, and graft function before and after transplantation. However, we were not able to measure bone mineral density in this study.

Several studies have reported that $25(\mathrm{OH}) \mathrm{D}$ deficiency is very common after renal transplantation. The most important reason is thought to be protection of patients from sunlight due to the increased risk of non-melanoma skin cancer associated with immunosuppressive therapy. In a recent study, a low 25(OH)D level 3 months after transplantation was demonstrated to be associated with renal fibrosis, renal tubular atrophy, and a low GFR after 1 year [17].

A circulating $25(\mathrm{OH}) \mathrm{D}$ level of less than $5 \mathrm{ng} / \mathrm{mL}$ is defined as severe deficiency, $15-29 \mathrm{ng} / \mathrm{mL}$ is insufficiency, above $30 \mathrm{ng} / \mathrm{mL}$ is normal, and more than $150 \mathrm{ng} / \mathrm{mL}$ is vitamin D intoxication, according to the National Kidney Foundation Kidney Disease Outcomes Quality Initiative (KDOQI) guideline. This guideline recommends beginning replacement therapy with vitamin D2 (ergocalciferol) when the $25(\mathrm{OH}) \mathrm{D}$ level is less than $30 \mathrm{ng} / \mathrm{mL}$ [18]. The Kidney Disease: Improving Global Outcomes guide also suggests measurement of the level of $25(\mathrm{OH}) \mathrm{D}$ in CKD patients in stages 1-5 and treatment of vitamin $D$ deficiency like the general population [19]. In our study, the 25(OH)D level was $7.74 \pm 6.59 \mathrm{ng} / \mathrm{mL}$ before transplantation, and this value increased to $10.46 \pm 5.79 \mathrm{ng} / \mathrm{mL}$ after transplantation. However, this increase was not statistically significant. No patient had a vitamin D level greater than $30 \mathrm{ng} / \mathrm{mL}$ in our study. In the study patients, $13 \%$ had vitamin D insufficiency and $87 \%$ had vitamin D deficiency before transplantation. Six months after transplantation, $27 \%$ had vitamin D insufficiency and $73 \%$ had vitamin $\mathrm{D}$ deficiency. The assessment of vitamin $\mathrm{D}$ deficiency remains difficult due to seasonal variations in serum $25(\mathrm{OH}) \mathrm{D}$. Analysis of seasonal changes in $25(\mathrm{OH}) \mathrm{D}$ has revealed that the serum level demonstrated a sinusoidal fluctuation throughout the year and was significantly higher in the summer. The response of $25(\mathrm{OH}) \mathrm{D}$ to seasonal variations was found to be $50 \%$ in the Turkish population [20]. Our data did not reveal a strong seasonal influence on vitamin $D$ status in renal transplant recipients, likely related to avoiding exposure to sunlight because of the increased risk of non-melanoma skin cancer associated with immunosuppressive therapy. Therefore, we believe that vitamin $D$ deficiency and insufficiency observed in renal transplant patients is independent of seasonal effects.

A high prevalence of vitamin $D$ insufficiency in patients with chronic renal disease has also been documented in literature. Our study focused on the association of a low vitamin $D$ level with proteinuria and graft function. A low $25(\mathrm{OH}) \mathrm{D}$ level has been associated with an increased prevalence of albuminuria among the general adult population [21]. An inverse relationship has been reported between vitamin $D$ level and protein- uria $[12,22]$. It is not well explained whether only urinary loss of vitamin $\mathrm{D}$ binding protein or $25(\mathrm{OH}) \mathrm{D}$ spontaneously contributed to vitamin $D$ insufficiency. Vitamin $D$ deficiency may also cause proteinuria by suppressing activation of the reninangiotensin system and it contributes to the reduction of proteinuria through hemodynamic mechanisms. Additionally, vita$\min \mathrm{D}$ deficiency leads to podocyte loss and glomerulosclerosis through direct cellular effects [23]. As seen in the literature, the results of this study indicated that proteinuria decreased with transplantation (Table 2). However, no significant correlation was observed between $25(\mathrm{OH}) \mathrm{D}$ and proteinuria. The reason may be the small sample size and limited number of transplanted patients with severe proteinuria.

Vitamin D may provide improvement in graft function and protect graft function. Keyzer et al. [24] reported that a low 25(OH) D level was associated with all causes of mortality and a marked annual reduction in renal function in their large scale study. We also evaluated the relationship between $25(\mathrm{OH}) \mathrm{D}$ level and graft function as assessed by eGFR. No significant correlation was shown between these parameters either before or after transplantation. Although the $25(\mathrm{OH}) \mathrm{D}$ level was measured at two time points, we did not observe change over time. Longer monitoring may be needed to fully evaluate any correlation between $25(\mathrm{OH}) \mathrm{D}$ level and graft function.

We observed a moderate level of 1,25(OH)2D3 before transplantation although there was the absence of adequate kidney function. This might be due to non-renal synthesis of $1,25(\mathrm{OH}) 2 \mathrm{D} 3$. The $1,25(\mathrm{OH}) 2 \mathrm{D} 3$ level showed a significant increase after transplantation due to the improvement of kidney function $(p=0.0001)$ (Table 2). The plasma 1,25(OH)2D3 level was similar to the post-transplantation findings of Keyzer et al. [24]; however, they reported that the association of low $1,25(\mathrm{OH}) 2 \mathrm{D} 3$ with mortality and graft failure depends on renal function.

Another point of our study was to examine the association between 25(OH)D, 1,25(OH)2D3 and PTH. In our study, the mean PTH level was higher than expected before transplantation. Although a significant and marked reduction in the PTH level was observed with transplantation, the level was still above the reference ranges. The low $25(\mathrm{OH}) \mathrm{D}$ level seen, even though renal function returned to normal, was related to the existence of hyperparathyroidism in our study. These findings may be explained according to the KDOQI. In the first year following renal transplantation, hyperparathyroidism persists in nearly $50 \%$ of recipients, despite the decrease in PTH level [8, 9].

Immunoassays are widely used for the measurement of serum/ plasma vitamin D metabolites. However, accurate quantification of these metabolites is difficult due to cross-reactivity. LC-MS/ MS is the gold standard method of analyzing these metabolites due to its high sensitivity and selectivity. The level of 1,25-dihydroxyvitamin D3 was measured using LC-MS/MS with an ESI source and compared with other parameters in our study. As a result of financial limitations, we could not measure vitamin $D$ using LC-MS/MS in this study. 
In conclusion, vitamin D insufficiency was still common after renal transplantation. Although it was associated with proteinuria among kidney transplant recipients, we could not significantly demonstrate this result in the present study due to some limitations, such as a small sample size and the need for longer monitoring. Additional, larger studies are necessary to evaluate our results and to determine whether vitamin $D$ may play an important role in the improvement of long-term graft function among kidney transplant recipients.

Acknowledgements: This study was supported by the Scientific Research Projects Coordination Unit of Akdeniz University (project number: 2014.02.0122.005).

Conflict of interest: None.

Ethical approval: All procedures performed in studies involving human participants were in accordance with the ethical standards of the Ethics Committee of Akdeniz University Faculty of Medicine (approval number: 225) at which the studies were conducted and with the 1964 Helsinki Declaration and its later amendments or comparable ethical standards.

Peer-review: Externally peer-reviewed.

Authorship contributions: Concept - B.K.E., H.A.; Design - B.K.E., H.A.; Supervision - H.A., V.T.Y, G.S.; Fundings - H.A.; Materials - B.K.E., V.T.Y.; Data collection \&/or processing - V.T.Y., G.S.; Analysis and/ or interpretation - B.K.E., F.Ö.; Literature search - A.B.A.; Writing B.K.E., H.A.; Critical review - H.A.

\section{References}

1. Hesketh CC, Knoll GA, Molnar AO, Tsampalieros A, Zimmerman DL. Vitamin D and kidney transplant outcomes: a protocol for a systematic review and meta-analysis. Syst Rev 2014;3:64.

2. Tonelli M, Wiebe N, Knoll G, Bello A, Browne S, Jadhav D, et al. Systematic review: kidney transplantation compared with dialysis in clinically relevant outcomes. Am J Transplant 2011;11:2093109. [CrossRef]

3. Pallardó Mateu LM, Sancho Calabuig A, Capdevila Plaza L, Franco Esteve A. Acute rejection and late renal transplant failure: risk factors and prognosis. Nephrol Dial Transplant 2004;19 Suppl 3:iii38-42. [CrossRef]

4. Knoll G, Muirhead N, Trpeski L, Zhu N, Badovinac K. Patient survival following renal transplant failure in Canada. Am J Transplant 2005;5:1719-24. [CrossRef]

5. Holick MF. Vitamin D deficiency. N Engl J Med 2007;357:266-81.

6. Holick MF. Vitamin D for health and in chronic kidney disease. Semin Dial 2005;18:266-75. [CrossRef]

7. González EA, Sachdeva A, Oliver DA, Martin KJ. Vitamin D insufficiency and deficiency in chronic kidney disease. A single center observational study. Am J Nephrol 2004;24:503-10.

8. Stavroulopoulos A, Cassidy MJ, Porter CJ, Hosking DJ, Roe SD. Vitamin D status in renal transplant recipients. Am J Transplant 2007;7:2546-52. [CrossRef]

9. National Kidney Foundation. K/DOQI clinical practice guidelines for bone metabolism and disease in chronic kidney disease. Am J Kidney Dis 2003;42:S1-201. [CrossRef]
10. Li YC, Kong J, Wei M, Chen ZF, Liu SQ, Cao LP. 1,25-Dihydroxyvitamin $D(3)$ is a negative endocrine regulator of the renin-angiotensin system. J Clin Invest 2002;110:229-38. [CrossRef]

11. Zhang Y, Kong J, Deb DK, Chang A, Li YC. Vitamin D receptor attenuates renal fibrosis by suppressing the renin-angiotensin system. J Am Soc Nephrol 2010;21:966-73. [CrossRef]

12. Lee DR, Kong JM, Cho KI, Chan L. Impact of vitamin D on proteinuria, insulin resistance, and cardiovascular parameters in kidney transplant recipients. Transplant Proc 2011;43:3723-9.

13. Prietl B, Treiber G, Pieber TR, Amrein K. Vitamin D and immune function. Nutrients 2013;5:2502-21. [CrossRef]

14. Boonstra A, Barrat FJ, Crain C, Heath VL, Savelkoul HF, O'Garra A. 1alpha,25-Dihydroxyvitamin $\mathrm{d} 3$ has a direct effect on naive CD4(+) T cells to enhance the development of Th2 cells. J Immunol 2001;167:4974-80. [CrossRef]

15. Yuan C, Kosewick J, He X, Kozak M, Wang S. Sensitive measurement of serum 1a,25-dihydroxyvitamin $D$ by liquid chromatography/tandem mass spectrometry after removing interference with immunoaffinity extraction. Rapid Commun Mass Spectrom 2011;25:1241-9. [CrossRef]

16. Bevc S, Hojs R, Ekart R, Gorenjak M, Puklavec L. Simple cystatin $C$ formula compared to sophisticated CKD-EPI formulas for estimation of glomerular filtration rate in the elderly. Ther Apher Dial 2011;15:261-8.

17. Bienaimé F, Girard D, Anglicheau D, Canaud G, Souberbielle JC, Kreis $\mathrm{H}$, et al. Vitamin $\mathrm{D}$ status and outcomes after renal transplantation. J Am Soc Nephrol 2013;24:831-41. [CrossRef]

18. Block GA, Port FK. Re-evaluation of risks associated with hyperphosphatemia and hyperparathyroidism in dialysis patients: recommendations for a change in management. Am J Kidney Dis 2000;35:1226-37. [CrossRef]

19. Kidney Disease: Improving Global Outcomes (KDIGO) CKDMBD Work Group. KDIGO clinical practice guideline for the diagnosis, evaluation, prevention, and treatment of Chronic Kidney Disease-Mineral and Bone Disorder (CKD-MBD). Kidney Int Suppl 2009:S1-130.

20. Serdar MA, Batu Can B, Kilercik M, Durer ZA, Aksungar FB, Serteser $M$, et al. Analysis of Changes in Parathyroid Hormone and $25(\mathrm{OH})$ Vitamin D Levels with Respect to Age, Gender and Season: A Data Mining Study. J Med Biochem 2017;36:73-83.

21. de Boer IH, loannou GN, Kestenbaum B, Brunzell JD, Weiss NS. 25-Hydroxyvitamin $\mathrm{D}$ levels and albuminuria in the Third National Health and Nutrition Examination Survey (NHANES III). Am J Kidney Dis 2007;50:69-77. [CrossRef]

22. Freundlich M, Quiroz Y, Zhang Z, Zhang Y, Bravo Y, Weisinger JR, et al. Suppression of renin-angiotensin gene expression in the kidney by paricalcitol. Kidney Int 2008;74:1394-402. [CrossRef]

23. Agarwal R, Acharya M, Tian J, Hippensteel RL, Melnick JZ, Qiu P, et al. Antiproteinuric effect of oral paricalcitol in chronic kidney disease. Kidney Int 2005;68:2823-8. [CrossRef]

24. Keyzer CA, Riphagen IJ, Joosten MM, Navis G, Muller Kobold AC, Kema IP, et al; NIGRAM consortium. Associations of $25(\mathrm{OH})$ and $1,25(\mathrm{OH}) 2$ vitamin $\mathrm{D}$ with long-term outcomes in stable renal transplant recipients. J Clin Endocrinol Metab 2015;100:81-9. 